\title{
Cryptococcus pinus sp. nov., an anamorphic basidiomycetous yeast isolated from pine litter
}

Correspondence

Wladyslav Golubev

wig@ibpm.pushchino.ru

\author{
Wladyslav I. Golubev, ${ }^{1}$ Ilona Pfeiffer ${ }^{2}$ and Maria A. Tomashevskaya ${ }^{1}$ \\ ${ }^{1}$ Russia Collection of Microorganisms (VKM), Institute for Biochemistry and Physiology of \\ Microorganisms, Russian Academy of Sciences, Pushchino 142290, Russia \\ ${ }^{2}$ Department of Microbiology, Faculty of Science and Informatics, University of Szeged, Szeged, \\ Hungary
}

\begin{abstract}
A novel species of the genus Cryptococcus, isolated from dead needles of Pinus sylvestris, was identified using mycocinotyping and rDNA sequence data. Phylogenetic analysis showed that the novel species was located in the Kwoniella clade of the Tremellales and was closely related to Cryptococcus dejecticola. The type strain of the novel species, Cryptococcus pinus sp. nov., is VKM Y-2958 $\left(=\right.$ CBS $\left.10737^{\top}\right)$.
\end{abstract}

Basidiomycetous yeasts of the genus Cryptococcus Vuillemin have been isolated from different environments and substrates and have a worldwide distribution (Golubev, 2002; Rosa \& Peter, 2006). Molecular studies have revealed the paraphyletic character of this genus that encompass species mainly within the hymenomycetous orders Tremellales and Filobasidiales, but also some species in the orders Trichosporonales and Cystofilobasidiales (Scorzetti et al., 2002). Moreover, so called 'ubiquitous' species [e.g. Cryptococcus albidus (Saito) Skinner and Cryptococcus laurentii (Kufferath) Skinner] are also taxonomically heterogeneous and represent groups of several distinct species (Fonseca et al., 2000; Takashima et al., 2003).

During a survey of the yeast community colonizing dead needles of pine litter, many isolates could be identified as C. laurentii, Cryptococcus flavescens (Saito) Skinner or Cryptococcus magnus (Lodder \& Kreger-van Rij) Baptist \& Kurtzman according to taxonomic keys and standard criteria used for differentiation (Fell \& Statzell-Tallman, 1998; Barnett et al., 2000). However, mycocinotyping showed that the isolates differed from the type strains of these species and from other members of the C. laurentii complex: Cryptococcus aureus (Saito) Takashima et al., Cryptococcus carnescens (Verona \& Luchetti) Takashima et al. and Cryptococcus peneaus (Phaff et al.) Takashima et al. Subsequent comparative studies of the new isolates by sequencing of the D1/D2 domains of the large subunit (LSU) rDNA and of the ITS region revealed that they were

\footnotetext{
Abbreviation: LSU, large subunit.
}

The GenBank/EMBL/DDBJ accession numbers for the D1/D2 region and ITS region of the rDNA gene of Cryptococcus pinus sp. nov. are EF672245 and EF672246, respectively.

A phylogenetic tree of Cryptococcus pinus sp. nov. and closely related species based on the alignment of ITS sequences is available as a supplementary figure with the online version of this paper. not conspecific with any known Cryptococcus species and should be assigned to a novel species.

The strains studied (isolation numbers: Ps-35, 38, 40A, 41, $51,52,55$ and 63) were isolated from dead needles collected underneath Pinus sylvestris $\mathrm{L}$. trees in a mixed forest (Moscow region, Russia) in October 2006. Serial dilutions of needle washings were plated onto pine needle agar and incubated at room temperature for 1-2 weeks. Needle infusion agar was prepared in the following manner: $200 \mathrm{~g}$ of dead pine needles was boiled in $1 \mathrm{l}$ of water for $10 \mathrm{~min}$. The liquid was filtered through gauze and water was added to the filtrate to make up 11 . After adding $20 \mathrm{~g}$ of agar, the medium was autoclaved for $15 \mathrm{~min}$ at $6.8 \mathrm{~kg}$ overpressure. After cooling to $50-60{ }^{\circ} \mathrm{C}$, streptomycin $(500 \mathrm{mg})$ was added and the medium was poured into sterile Petri dishes. Other strains used in this study were from the Russia Collection of Microorganisms (VKM; http://www.vkm.ru/). For morphological and physiological characterization, standard methods currently employed in yeast taxonomy were used (Yarrow, 1998).

Genomic DNA was extracted using MasterPure yeast DNA purification kit (Epicentre Biotechnologies). The primers used for PCR amplification and sequencing of the D1/D2 region of the $26 \mathrm{~S}$ rDNA were NL-1 (5'-GCATATCAATAAGCGGAGGAAAAG- $3^{\prime}$ ) and NL-4 (5'-GGTCCGTGTTTCAAGACGG- $3^{\prime}$. The ITS $5.8 \mathrm{~S}$ region was amplified and sequenced with primers ITS1 (5'-TCCGTAGGTGAACCTGCGG-3') and ITS4 (5'-TCCTCCGCTTATTGATATGC-3'). The reaction mixture contained $200 \mu \mathrm{M}$ of each dNTP, 25 pmol of each primer, $2.5 \mathrm{U}$ Taq DNA polymerase and $200 \mathrm{ng}$ genomic DNA. The mixture was buffered with $10 \mathrm{mM}$ Tris/ $\mathrm{HCl}(\mathrm{pH} \mathrm{9.0)}, 50 \mathrm{mM} \mathrm{KCl}$, $1.5 \mathrm{mM} \mathrm{MgCl} 2$ and $0.1 \%$ Triton X-100. The amplification was carried out in a PTC-100 programmable thermal controller (MJ Research Inc.). The PCR reaction consisted of an initial denaturation for $5 \mathrm{~min}$ at $94{ }^{\circ} \mathrm{C}$ followed by 35 
cycles of 1 min denaturation at $94{ }^{\circ} \mathrm{C}$, annealing for $30 \mathrm{~s}$ at $55{ }^{\circ} \mathrm{C}$ and extension for $1 \mathrm{~min}$ at $72{ }^{\circ} \mathrm{C}$. The final extension step was carried out at $72{ }^{\circ} \mathrm{C}$ for $5 \mathrm{~min}$. The PCR products were purified with the High Pure PCR product purification kit (Roche Diagnostics). Sequencing of both strands was performed with an ABI 3100 sequencer (Applied Biosystems). The sequence data were deposited in the National Center for Biotechnology Information (NCBI) online service database.

The phylogenetic position of the yeast under study was estimated using the maximum-parsimony, neighbourjoining and Bayesian phylogenetic reconstruction methods based on the D1/D2 and ITS1-5.8S-ITS2 sequences, independently. DNA sequences were aligned using CLUSTAL_X v1.83 (Thompson et al., 1994). The effect of alignment (removing ambiguous regions, manual corrections) on phylogenetic inference was tested by comparing tree topologies obtained by independent reconstructions. The topology was generally not affected by the inclusion or exclusion of unalignable regions or gaps as separate characters. The results of the Bayesian reconstruction are presented. The symmetrical model with a gamma rate distribution across sites (SYM +G, Zharkikh, 1994) was suggested as an appropriate model of molecular evolution (MODELTeST v3.7, Posada \& Crandall, 1998) for both regions. Bayesian phylogenetic inference was performed with MrBayes v3.1 (Ronquist \& Huelsenbeck, 2003). For both data matrices, each search was performed in two independent runs with four simultaneous chains initializing with a flat prior distribution. Chains were run for two million generations where every 100 generations were sampled after a burning of 750000 generations. Suitable convergence was achieved in all cases. Trees were rooted to Filobasidiella neoformans var. neoformans ATCC 32045, mating type $\alpha$, serotype D (D1/D2 GenBank accession no. AF335984; ITS GenBank accession no. AF162916).
The procedure for determining mycocin sensitivity patterns has been described previously (Golubev et al., 2006).

The strains studied were almost identical in cultural, morphological and physiological characteristics. Pairwise mixing of strains on cornmeal agar did not result in any mating reactions. The following properties of the novel isolates placed them in the genus Cryptococcus: asexual reproduction by budding, ballistoconidia and arthroconidia not produced, no alcoholic fermentation, a positive urease test, the assimilation of i-inositol and D-glucuronate, and the production of starch-like compounds. The strains did not utilize nitrate and resembled species of the C. laurentii complex in carbon assimilation profiles. However, significant differences in sensitivity to mycocins were found between the novel isolates and other species (Table 1). The taxonomic specificity of sensitivity to mycocins has already been shown (Golubev, 1998; Golubev \& Golubeva, 2006) and the differences observed in this study suggested that the new strains represent a novel species.

Molecular sequence data confirmed this suggestion, further indicating that the new taxon is a sister group of Cryptococcus dejecticola Thanh et al. differing by six mismatches (out of 591 nucleotides) in the D1/D2 domain of the LSU rDNA (Fig. 1). More discrepancies (eight gaps and 21 nucleotide mismatches in 554 positions) were observed in the ITS region (see Supplementary Fig. S1. in IJSEM Online). Alternative sequence alignments affected only the placement of Bullera dendrophila but the $C$. dejecticola-Cryptococcus pinus group was supported by high posteriori probability in all cases.

Our isolates were also distinct from $C$. dejecticola (Thanh et al., 2006) in the assimilation of inulin, erythritol, salicin, arbutin, soluble starch, ethanol and lactate, in the utilization of glucosamine as nitrogen source, and in the

Table 1. Mycocin sensitivity patterns of phenotypically resembling Cryptococcus species

Taxa: 1, C. carnescens VKM Y-720 ${ }^{\mathrm{T}}$; 2, C. pinus sp. nov. VKM Y-2958 ${ }^{\mathrm{T}}$; 3, C. perniciosus VKM Y-2905 ${ }^{\mathrm{T}}$; 4, C. nemorosus VKM Y-2906 ${ }^{\mathrm{T}}$; 5, C. magnus VKM Y-1550 ${ }^{\mathrm{T}}$; 6, C. peneaus VKM Y-1291 $;$ 7, C. aureus VKM Y-328 ${ }^{\mathrm{T}}$ 8, C. flavescens VKM Y-1595 ${ }^{\mathrm{T}}$; 9, C. laurentii VKM Y-1665 ${ }^{\mathrm{T}}$; 10 , C. heveanensis VKM Y-1457 ${ }^{\mathrm{T}}$. + , Sensitive; $\mathrm{W}$, weakly sensitive; - , non-sensitive; $\mathrm{X}$, not applicable.

\begin{tabular}{|c|c|c|c|c|c|c|c|c|c|c|}
\hline Mycocinogenic strains & 1 & 2 & 3 & 4 & 5 & 6 & 7 & 8 & 9 & 10 \\
\hline Filobasidium capsuligenum VKM Y-1439 & - & - & - & - & - & - & - & - & $\mathrm{w}$ & + \\
\hline Cryptococcus nemorosus VKM Y-2906 ${ }^{\mathrm{T}}$ & - & - & - & $\mathrm{x}$ & - & - & - & + & + & + \\
\hline Bullera unica VKM Y-2830 & - & - & - & - & - & $\mathrm{W}$ & $\mathrm{W}$ & - & + & + \\
\hline Bullera alba VKM Y-2829 & + & - & - & - & - & + & - & + & + & + \\
\hline Bullera sinensis var. lactis VKM Y- $2826^{\mathrm{T}}$ & $\mathrm{W}$ & - & + & + & + & - & $\mathrm{W}$ & + & + & + \\
\hline Cystofilobasidium bisporidii VKM Y-2700 & - & + & - & + & $\mathrm{w}$ & + & + & + & - & + \\
\hline Cryptococcus laurentii VKM Y-1665 & - & + & + & + & + & $\mathrm{w}$ & + & + & $\mathrm{x}$ & + \\
\hline Cryptococcus perniciosus VKM Y- $2905^{\mathrm{T}}$ & + & + & $\mathrm{x}$ & - & $\mathrm{w}$ & + & + & + & + & + \\
\hline
\end{tabular}




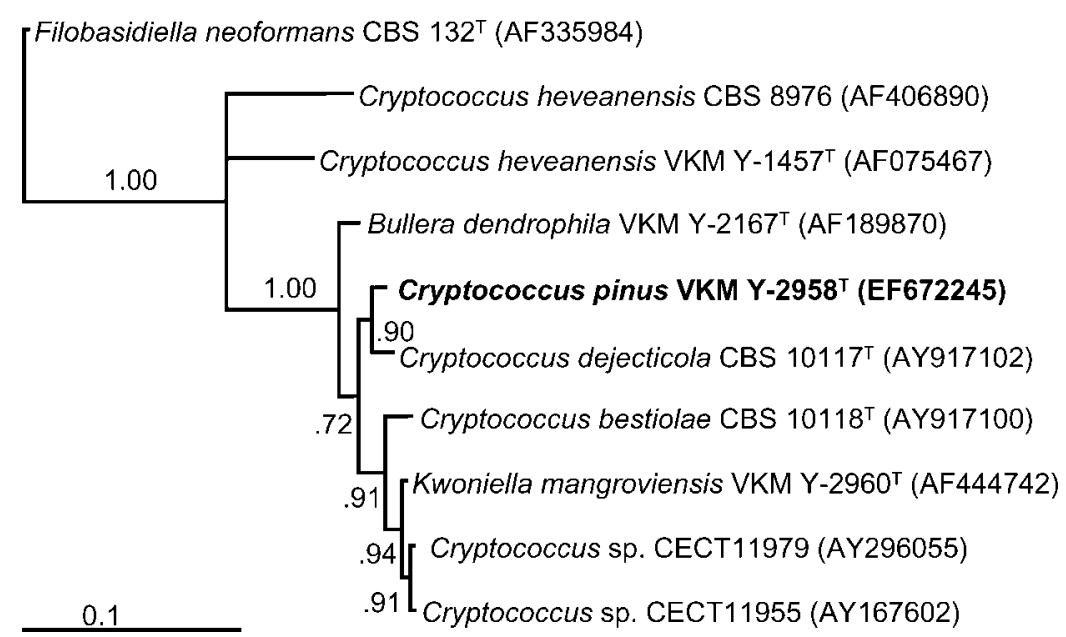

Fig. 1. Bayesian phylogenetic tree of Cryptococcus pinus sp. nov. and closely related species based on the alignment of D1/D2 LSU rDNA sequences. Posterior probabilities are also shown. Tree was rooted to Filobasidiella neoformans. The GenBank accession numbers of the sequences are indicated after the strain numbers. Bar, 0.1 substitutions per site. ability to grow in vitamin-free medium. All these findings have led us to conclude that the strains under study cannot be assigned to any known species of the genus Cryptococcus. Consequently, the novel species Cryptococcus pinus sp. nov. is proposed.

Phylogenetically C. pinus is a close relative of the teleomorphic yeast Kwoniella mangroviensis StatzellTallman et al. (2008) (Fig. 1). Beside C. pinus, the Kwoniella clade includes the anamorphic tremellaceous species Cryptococcus bestiolae Thanh et al., C. dejecticola, Cryptococcus heveanensis (Groenewege) Baptist \& Kurtzman and the ballistoconidium-forming yeast Bullera dendrophila van der Walt \& Scott, serving as one more example of the mutual polyphyly of Cryptococcus and Bullera Derx species (Scorzetti et al., 2002). It should be noted that cultures of Bullera spp. easily lose the ability to produce ballistoconidia, their main diagnostic characteristic. A search for clear-cut phenotypic discriminatory criteria that are congruent with sequence-based phylogenies is currently of prime importance for yeast taxonomy.

\section{Latin diagnosis of Cryptococcus pinus Golubev et Pfeiffer sp. nov.}

In aqua glucosum et peptonum et extractum fermenti continente, post dies 3 cellulae globosae, subglobose et ovoidae $(2.6-8.5 \times 3.4-12.8 \mu \mathrm{m})$, incapsulate, singulae vel binae. Post unum mensem sedimentum, annulus et insulae formantur. In agaro morphologico (Difco) post unum mensem cultura in striis griseocremea, glabra, nitida, mucosa; margo integra. Ballistoconidia nullae. Nec mycelium nec pseudomycelium formatur. Status sexualis non apparet. Non fermentat. Glucosum, galactosum, $\alpha$-methylglucosidum (lente), ribosum, xylosum, L-arabinosum, D-arabinosum (lente), L-rhamnosum (lente), sucrosum, maltosum, trehalosum (lente), cellobiosum, lactosum, melezitosum, raffinosum (lente), arbutinum (lente), salicinum (lente), amylum (lente), ethanolum (lente), glycerolum, xylitolum (lente), arabitolum (lente), glucitolum, mannitolum, galactitolum, inositolum, glucuronatum, gluconatum, 2-ketogluconatum, 5-ketogluconatum, glucaratum (lente), succinatum, citratum (exigue), lactatum (lente) et glycinum (exigue) assimilantur neque glucosaminum, $N$-acetylglucosaminum, L-sorbosum, melibiosum, erythritolum, acidum quinicum et allantoinum. Assimilatio inulinum variabilis (exigue aut nulla). Kalium nitosum, lysinum, ethylaminum (lente), glucosaminum, cadaverinum (lente) et tryptophanum assimilantur, kalium nitricum, creatinum et creatininum non assimilantur. Urea finditur. Vitamina externa at crescentiam necesseria sunt. Materia amyloidea iodophila formantur. Maxima temperatura crescentiae: $32{ }^{\circ} \mathrm{C}$. Typus Ps $-38^{\mathrm{T}}$ isolates ex foliis acicularibus Pinus sylvestris L. delapsis (Rossia), conservatur in collectione micro-organismorum (=VKM Y-2958 ${ }^{\mathrm{T}}$ ) Acad. Sci. Rossicum (Pushczino, Rossia) et in collectione zymotica $\left(=\mathrm{CBS} 10737^{\mathrm{T}}\right)$ Centraalbureau voor Schimmelcultures (Utrecht, Hollandia).

\section{Description of Cryptococcus pinus Golubev \& Pfeiffer sp. nov.}

Cryptococcus pinus (pi'nus. L. gen. n. pinus of pine, referring to the origin of the strains, which were isolated from pine litter).

After 3 days in glucose-yeast extract-peptone broth, cells are globose, subglobose and oval [width/length ratio 1.0-2.2 (mean 1.3)], 2.6-8.5 ×3.4-12.8 $\mu \mathrm{m}$ (mean $4.0 \times 5.4 \mu \mathrm{m}$ ) with capsules and single or in pairs (Fig. 2). After 1 month, there is a sediment, a ring and islets. After 1 month, the streak culture on yeast morphology agar (Difco) is greyish cream, smooth, glistening and slimy with an entire margin. No ballistoconidia are observed. After 10 days in slide cultures on cornmeal agar, neither true mycelium nor pseudomycelium is produced. Fermentation is absent. The following carbon compounds are assimilated: D-glucose, galactose, methyl $\alpha$-D-glucoside (slow), Dribose, D-xylose, L-arabinose, D-arabinose (slow), L-rhamnose (slow), sucrose, maltose, trehalose (slow), cellobiose, lactose, melezitose, raffinose (slow), arbutin (slow), salicin (slow), soluble starch (slow), ethanol (slow), glycerol, 


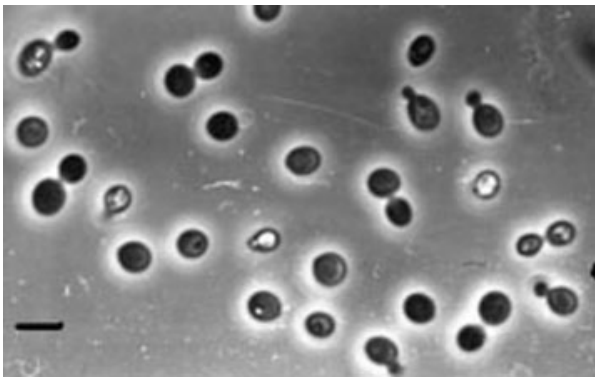

Fig. 2. Cells of Cryptococcus pinus sp. nov. VKM Y-2958 ${ }^{\top}$ grown on malt agar at $20^{\circ} \mathrm{C}$ for 3 days. Phase-contrast. Bar, $5 \mu \mathrm{m}$.

xylitol (slow), L-arabitol (slow), sorbitol, mannitol, galactitol, i-inositol, D-glucuronate, D-gluconate, 2-keto-Dgluconate, 5-keto-D-gluconate, glucarate (slow), succinate, citrate (weak), lactate (slow) and glycine (weak). No growth occurs on D-glucosamine, $\mathrm{N}$-acetylglucosamine, Lsorbose, melibiose, erythritol, quinic acid or allantoin. Assimilation of inulin is variable (weak or negative). Utilization of nitrogen compounds: positive for nitrite, Llysine, ethylamine (slow), D-glucosamine, cadaverine (slow) and D-tryptophan, negative for nitrate, creatine and creatinine. Positive for urease activity. Does not grow in vitamin-free medium. Produces starch-like compounds. Maximum temperature for growth is $32{ }^{\circ} \mathrm{C}$. Strains are sensitive to the mycocins produced by Cryptococcus laurentii VKM Y-1665, Cryptococcus perniciosus VKM Y2905, Cryptococcus podzolicus VKM Y-2247 and Cystofilobasidium bisporidii VKM Y-2700, but are resistant to the mycocins of Bullera alba VKM Y-2829, Bullera hannae VKM Y-2832, Bullera sinensis var. lactis VKM Y2826, Bullera unica VKM Y-2830, Cryptococcus laurentii VKM Y-1628, Cryptococcus nemorosus VKM Y-2906, Cryptococcus podzolicus VKM Y-2249, Cystofilobasidium infirmominiatum VKM Y-2897 and Filobasidium capsuligenum VKM Y-1439.

The type strain, Ps- $38^{\mathrm{T}}\left(=\mathrm{VKM} \mathrm{Y}-2958^{\mathrm{T}}=\mathrm{CBS} 10737^{\mathrm{T}}\right)$, was isolated from dead needles of Pinus sylvestris $\mathrm{L}$. in the Moscow region (Russia) and has been deposited in the Russia Collection of Microorganisms (Pushchino, Russia) and in the Yeast Collection of the Centraalbureau voor Schimmelcultures (Utrecht, the Netherlands).

\section{Acknowledgements}

M.-A. Lachance is acknowledged for correcting the English text.

\section{References}

Barnett, J. A., Payne, R. W. \& Yarrow, D. (2000). Yeasts: Characteristics and Identification, 3rd edn, Cambridge: Cambridge University Press.

Fell, J. W. \& Statzell-Tallman, A. (1998). Cryptococcus Vuillemin. In The Yeasts: a Taxonomic Study, 4th edn, pp. 742-767. Edited by C. P. Kurtzman \& J. W. Fell. Amsterdam: Elsevier.

Fonseca, A., Scorzetti, G. \& Fell, J. W. (2000). Diversity in the yeast Cryptococcus albidus and related species as revealed by ribosomal DNA sequence analysis. Can J Microbiol 46, 7-27.

Golubev, W. I. (1998). Mycocins (killer toxins). In The Yeasts: a Taxonomic Study, 4th edn, pp. 55-62. Edited by C. P. Kurtzman \& J. W. Fell. Amsterdam: Elsevier.

Golubev, W. I. (2002). The genus Cryptococcus and its type species, Cryptococcus neoformans. In An Update on Systematics and Nomenclature of Fungi, pp. 357-381. Edited by Y. T. Dyakov \& Y. V. Sergeev. Moscow: Natl. Acad. Mycol.

Golubev, W.I. \& Golubeva, E.W. (2006). Mycocinotyping of filobasidiaceous species in the genus Cryptococcus. Mykologia $i$ Phytopathologia 40, 480-486.

Golubev, W. I., Sampaio, J. P., Alves, L. \& Golubeva, E. W. (2006). Cryptococcus silvicola nov. sp. from nature reserves of Russia and Portugal. Antonie van Leeuwenhoek 89, 45-51.

Posada, D. \& Crandall, K. A. (1998). MODELTEST: testing the model of DNA substitution. Bioinformatics 14, 817-818.

Ronquist, F. \& Huelsenbeck, J. P. (2003). MrBayes 3: Bayesian phylogenetic inference under mixed models. Bioinformatics 19, 1572-1574.

Rosa, C. A. \& Peter, G. (editors) (2006). Biodiversity and Ecophysiology of Yeasts. Berlin: Springer.

Scorzetti, G., Fell, J. W., Fonseca, A. \& Statzell-Tallman, A. (2002). Systematics of basidiomycetous yeasts: a comparison of large subunit D1/D2 and internal transcribed spacer rDNA regions. FEMS Yeast Res 2, 495-517.

Statzell-Tallman, A., Belloch, C. \& Fell, J. W. (2008). Kwoniella mangroviensis gen. nov., sp. nov. (Tremellales, Basidiomycota), a teleomorphic yeast from mangrove habitats in the Florida Everglades and Bahamas. FEMS Yeast Res 8, 103-113.

Takashima, M., Sugita, T., Shinoda, T. \& Nakase, T. (2003). Three new combinations from the Cryptococcus laurentii complex: Cryptococcus aureus, Cryptococcus carnescens and Cryptococcus peneaus. Int J Syst Evol Microbiol 53, 1187-1194.

Thanh, V. N., Hai, D. A. \& Lachance, M.-A. (2006). Cryptococcus bestiolae and Cryptococcus dejecticola, two new yeast species isolated from frass of the litchi fruit borer Conopomorpha sinensis Bradley. FEMS Yeast Res 6, 298-304.

Thompson, J. D., Higgins, D. G. \& Gibson, T. J. (1994). CLUSTAL W improving the sensitivity of progressive multiple sequence alignment through sequence weighting, position-specific gap penalties and weight matrix choice. Nucleic Acids Res 22, 4673-4680.

Yarrow, D. (1998). Methods for the isolation, maintenance and identification of yeasts. In The Yeasts, a Taxonomic Study, 4th edn, pp. 77-100. Edited by C. P. Kurtzman \& J. W. Fell. Amsterdam: Elsevier.

Zharkikh, A. (1994). Estimation of evolutionary distances between nucleotide sequences. J Mol Evol 39, 315-329. 